\title{
Distribution of Brazilian dermatologists according to geographic location, population and HDI of municipalities: an ecological study*
}

\author{
Juliano Vilaverde Schmitt ${ }^{1}$
}

Hélio Amante Miot ${ }^{1}$

\begin{abstract}
This study investigated the geographic distribution of dermatologists in Brazilian municipalities in relation to the population, regions of the country and human development index. We conducted an ecological study based on data from the 2010 census, the 2010 human development index, and the records of the Brazilian Society of Dermatology. 5565 municipalities and 6718 dermatologists were surveyed. Only 504 (9.1\%) municipalities had dermatologists, and accounted for $56.2 \%$ of the Brazilian population. The smallest population size and lowest HDI rate that best discriminated municipalities that did not have dermatologists were found to be 28,000 and 0.71 , respectively. The average population density of dermatologists in cities was $1 / 23.000$ inhabitants, and variations were independently associated with the HDI, the population of the municipalities and the region of the country.
\end{abstract}

Keywords: Dermatology; Human development; Social indicators

The Brazilian population's demand for dermatology services is not properly defined, nor is the adequate number of professionals for health coverage by this branch of medicine..$^{1-3}$

The geographical distribution of dermatologists in Brazil is quite heterogeneous, and concentrates in more populous cities. In addition, there are regional differences in care (waiting lists and costs of medical appointments), which suggests that other factors may influence the settling of these professionals. ${ }^{4}$

The Human Development Index (HDI) is a tool developed by the United Nations in 1990 to measure levels of social and economic development and rank population groups based on three indices: longevity (HDI-L), education (HDI-E) and income (HDI-I). ${ }^{5}$

In order to investigate social, political and geographic factors that may influence the professional settlement of specialists, this study investigated the national distribution of dermatologists in relation to population size of municipalities, regions of the country and HDI.
We conducted an ecological study involving all Brazilian municipalities, and based on data from the 2010 census, the $2010 \mathrm{HDI}$, the Brazilian Society of Dermatology (BSD) and the Federal Council of Medicine (FCM) ${ }^{6,7}$

The best discriminating points between the presence of dermatologist in municipalities and population or HDI were determined by the ROC curve. We evaluated the correlation between per capita density of professionals, HDI and its components (HDI-I, HDI-E and HDI-L), and number of doctors, by using the Spearman's rank correlation coefficient (rs). The population density of dermatologists was assessed in multivariate analysis using generalized linear model. Statistically significant value was considered at $\mathrm{p}<0.01{ }^{8}$

5565 municipalities and 6718 dermatologists were surveyed. Dermatologists were present in only $504(9.1 \%)$ municipalities, which accounted for $56.2 \%$ of the Brazilian population.

The analysis showed high correlation between the number of dermatologists and the population (rs =

\footnotetext{
Received on 21.11.2013.

Approved by the Advisory Board and accepted for publication on 19.12.2013.

* Study conducted at the Dermatology and Radiotherapy Department, Botucatu Medical School, Sao Paulo State University Julio de Mesquita Filho (Unesp) Botucatu (SP), Brazil.

Conflict of interest: None

Financial funding: None

Universidade Estadual Paulista "Julio de Mesquita Filho" (Unesp) - Botucatu (SP), Brazil.
} 
$0.77, \mathrm{p}<0.01)$, and between the number of dermatologists and number of physicians ( $\mathrm{rs}=0.86, \mathrm{p}<0.01$ ) in cities that had dermatologists.

The lowest population size and HDI rate that best discriminated municipalities with and without dermatologists were found to be 25-31 thousand (area under ROC curve $=95 \%$ ), and 0.70-0.72 (area under ROC curve $=89 \%$ ). However, there were variations among the regions of the country. Figure 1 shows Brazilian municipalities according to their population, HDI and presence of dermatologists.

Similarly, we also observed a greater concentration of Brazilian doctors registered in the FCM in cities with a HDI higher than $0.71(29 \times 3 / 10,000$ inhabitants)
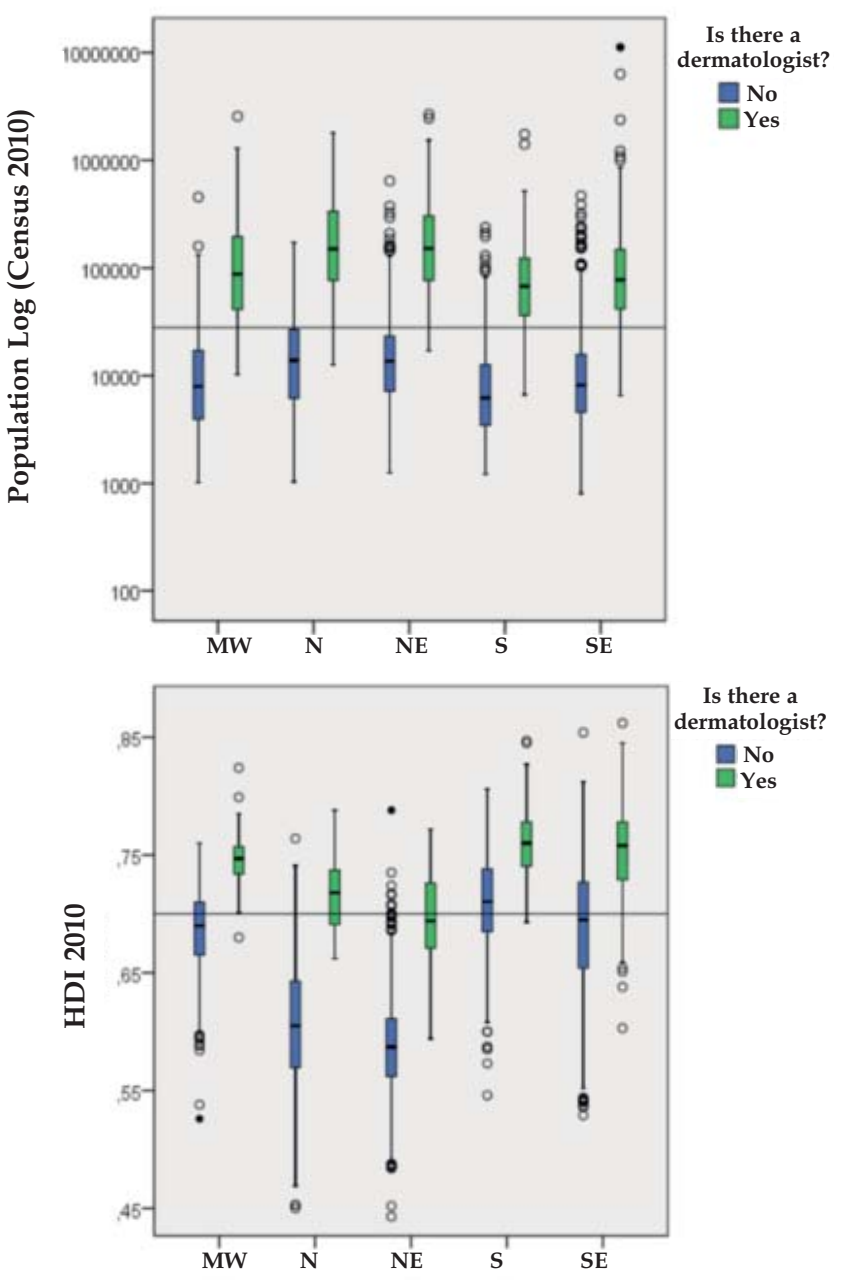

Horizontal lines indicating 28,000 inhabitants (A) and HDI 0.71 (B).

FIGURE 1: Distribution of populations (A) and HDI (B) of municipalities (Log) according to the presence of dermatologists and the region of Brazil *
The total number of dermatologists was positively correlated with the HDI of municipalities that had experts ( $r s=0.51, p<0.01)$. The highest rates were found for the HDI-I ( $\mathrm{rs}=0.52, \mathrm{p}<0.01$ ) and the lowest rates were found for the HDI-E $(\mathrm{rS}=0.48, \mathrm{p}<0.01)$ and HDI-L ( $\mathrm{rs}=0.17, \mathrm{p}<0.01$ ).

The presence of one or more dermatologists in the municipalities was independently associated with the HDI, the population of the municipalities and the region of the country. Effect of interaction was found between population and HDI ( $\mathrm{p}<0.01)$.

The average population density of dermatologists in cities was $1 / 23.000$ inhabitants, ranging from a minimum occurrence of $1 / 303.000$ and a maximum of $1 / 3.000$. Its variation among the cities that had dermatologists was associated with the HDI, the population and region of the country. Effect of interaction was found between population and HDI ( $p<0.01)$.

Table 1 shows the mean proportion of dermatologists, according to the region, HDI and population of the municipalities.

The study revealed that the heterogeneity in the distribution of dermatologists in Brazil is associated with factors of human development, political and geographical distribution and size of municipalities. This leads to the hypothesis that, in order to be successful, programs to increase the number of physicians in underserved cities should consider political subsidies, public development subsidies and comprehensive support services for professional career development.

Although less than $10 \%$ of the total municipalities in the country had dermatologists, more than half of the Brazilian population lives in these areas. Moreover, if we consider the commuting of patients from neighboring cities, or even the performance of a single professional in different cities, the proportion of population coverage should be even higher. ${ }^{9}$ However, the geographic heterogeneity of Brazilian dermatological health coverage may incite non-specialist professionals to exercise this function.

The HDI is a standardized indicator of the wellbeing of a population. In 2011, Brazil was ranked 84th in the world (HDI $=0.72$ ). Nevertheless, the distribution of municipalities is very heterogeneous: more than 500 show low development rates (HDI <0.54) and only 56 cities present very high development rates $(\mathrm{HDI}>0.80)$.

When considered concomitantly, HDI and population of the municipalities influence the distribution of dermatologists in different regions of the country. There is a higher density of professionals in populated areas and areas with higher HDI values, and even smaller density of experts in municipalities of the Northern region.

The high correlation between the number of 
TABLE 1: Number of dermatologists by 100.000 inhabitants (weighted average) in relation to HDI and municipality's population, in the different regions

\begin{tabular}{lcccc}
\hline Region & HDI & Population & \\
\hline \multirow{3}{*}{ South } & & $\mathbf{2 5 - 1 0 0 . 0 0 0}$ & $\mathbf{1 0 0 - 3 0 0 . 0 0 0}$ & $>\mathbf{3 0 0 . 0 0 0}$ \\
& $<0,71$ & 0,26 & - & NA \\
Southeast & $>0,71$ & 2,31 & 3,28 & 9,83 \\
\multirow{2}{*}{ Midwest } & $<0,71$ & 1,42 & 0,28 & - \\
\multirow{2}{*}{ North } & $>0,71$ & 2,52 & 3,81 & NA \\
\multirow{2}{*}{ Northeast } & $>0,71$ & 0,25 & 0,19 & 6,71 \\
& $>0,71$ & 1,25 & 2,21 & NA \\
& $>0,71$ & 0,07 & 0,66 & 3,71 \\
Total & $>0,71$ & 2,46 & 2,25 & 1,69 \\
& $>0,71$ & 0,11 & 0,60 & 5,51 \\
\hline
\end{tabular}

NA: There are no municipalities in this category

dermatologists and the number of other physicians in cities supports the hypothesis that municipalities with better urban infrastructure and higher income levels of the population favor the settlement of physicians in general, not only dermatologists. ${ }^{4,10}$

The main limitations of the study are related to its ecological features, because they do not allow us to establish causality based on the correlations analyzed. Moreover, other factors are not evaluated, such as: internal migration, cities that offer training services to professionals, dermatologists who work in more than one municipality, inaccuracy of the records of the BSD and dermatological care provided by professionals who are not members of the BSD.

\section{REFERENCES}

1. Mansur MC, Mansur J, Mansur L, Gonçalves BC, Pereira RN. Distribuição Geográfica dos Dermatologistas do Brasil em 1999. Análise do mercado de trabalho em 13 anos. An Bras Dermatol. 2001;76:467-82.

2. Resneck J. Too few or too many dermatologists? Difficulties in assessing optimal workforce size. Arch Dermatol. 2001;137:1295-301.

3. Resneck JS Jr, Kimball AB. Who else is providing care in dermatology practices? Trends in the use of nonphysician clinicians. J Am Acad Dermatol. 2008;58:211-6.

4. Miot HA, Miot LDB. Time needed to schedule dermatological consultations in Brazil. An Bras Dermatol. 2013;88:563-9.

5. Hdr.unfp.org. [Internet]. Human Development. Human Development Reports (HDR). United Nations Development Programme (UNDP). [cited 2013 Oct 2]. Available from: http://hdr.undp.org/en/humandev/

6. Portal.cmf.org.br [Internet]. Busca de médicos. [acesso 2 Out 2013]. Disponível em: http://portal.cfm.org.br/index.php?option =com medicos\&ltemid $=59$

7. Sbd.org.br [Internet]. Sociedade Brasileira de Dermatologia, Dermatologia ao alcance de todos. [acesso 2 Out 20132]. Disponível em: http://www.sbd.org.br/

8. Norman GR, Streiner DL. The bare essentials. Shelton, Connecticut: People's Medical Publishing House; 2008.

9. Brito F. 0 deslocamento da população brasileira para as metrópoles. Estu Av. 2006;20:221-36.

10. Póvoa L, Andrade MV. Distribuição geográfica dos médicos no Brasil: uma análise a partir de um modelo de escolha locacional. Cad Saúde Pública. 2006;22:1555-64.

\author{
MAILING ADDRESS: \\ Juliano Vilaverde Schmitt \\ Departamento de Dermatologia e Radioterapia \\ Faculdade de Medicina da Unesp, S/N \\ Campus Universitário de Rubião Jr. \\ 18618-970 - Botucatu - SP \\ Brazil. \\ E-mail:julivs@gmail.com
}

How to cite this article: Schmitt JV, Miot HA. Distribution of Brazilian dermatologists according to geographic location, population and HDI of municipalities: an ecological study. An Bras Dermatol. 2014;89(6):1013-5. 